\title{
Synthesis
}

\section{A Review of Design Principles for Community-based Natural Resource Management}

\author{
$\underline{\text { Michael Cox }}^{1}, \underline{\text { Gwen Arnold }}^{1}$, and $\underline{\text { Sergio Villamayor Tomás }}^{1}$
}

\begin{abstract}
In 1990, Elinor Ostrom proposed eight design principles, positing them to characterize robust institutions for managing common-pool resources such as forests or fisheries. Since then, many studies have explicitly or implicitly evaluated these design principles. We analyzed 91 such studies to evaluate the principles empirically and to consider what theoretical issues have arisen since their introduction. We found that the principles are well supported empirically and that several important theoretical issues warrant discussion. We provide a reformulation of the design principles, drawing from commonalities found in the studies.
\end{abstract}

Key Words: common-pool resources; design principles; diagnostics; institutions

\section{INTRODUCTION}

\section{The challenge of complexity}

Scholars in the social sciences have only recently begun to deal with the challenges involved in analyzing complex systems. The central problem is the large number of relevant variables and their interactions that affect how human systems operate at multiple levels. This complexity increases when social systems interact with natural systems that present similar analytical difficulties. Communities of users managing common-pool resources (CPRs) such as forests or fisheries are excellent examples of this complexity. Understanding these situations is important given the increasing impact humans are having on the environment and the important role that communities often play in natural resource management in diverse settings worldwide.

Until the 1980s, many scholars had presumed that the users of such resources could not self-organize to manage them. Thus, scholars often recommended the imposition of government or private ownership based on the theories of Gordon (1954), Demsetz (1967), and Hardin (1968). Scholarly reports during the mid-1980s, however, began to raise serious questions about the wisdom of massive efforts to impose particular institutional arrangements on the users of CPRs (Feeny et al. 1990).
In 1983, the National Research Council established a research committee to examine the problems facing the users of CPRs, bringing together scholars from a wide diversity of disciplines to review the existing empirical evidence about CPRs and the impacts of diverse governance arrangements. A report was published in 1986 that criticized the confusion related to property regimes for CPRs and recommended the need for further research on how diversely structured systems for governing and managing CPRs perform in the field (National Research Council 1986). The report argued that the complexity of the systems used to manage CPRs in the field had confused scholars into thinking that chaos prevailed unless simple government or private-property systems were imposed.

\section{Previous analyses of common-pool resources}

Concurrently with these events, colleagues at the Workshop in Political Theory and Policy Analysis at Indiana University in Bloomington, Indiana, USA, created a database to record key information from the growing number of case studies found in the literature related to how self-organized regimes manage CPRs. The database included variables describing the structure of the resource systems, the history of the people involved, the rules in use, the organizations involved, the amount of resource units harvested, and the conditions of the resource. 
A core question pursued by the group was: What type of rules appear to be most successful in sustaining the productive use of CPRs?

Although it appeared that some common attributes were shared by the long-surviving CPR systems, these were not in the form of specific institutional rules such as those propounded in the literature. In Ostrom's (1990) textbook Governing the commons: the evolution of institutions for collective action, she drew on this work to posit a set of eight general design principles that appeared to characterize the efficacy of multiple types of rules and sets of rules.

While the formulation of principles associated with successful collective action in CPR governance is a challenging endeavor, it is equally important to understand the mechanisms underlying these associations. A full account of the theoretical mechanisms and the models of human behavior involved is beyond the scope of our analysis. The model of the individual that Ostrom (1990:185) relied on consisted of "fallible, norm-adopting individuals who pursue contingent strategies in complex and uncertain environments." The institutional design principles then follow North's (1990) conception of institutions as mechanisms for reducing uncertainty in complex, uncertain environments. By reducing uncertainty, trust and norms of reciprocity may be built and sustained, and collective action may become possible. In this context, the primary role of the design principles is to explain under what conditions trust and reciprocity can be built and maintained to sustain collective action in the face of social dilemmas posed by CPRs. This collective action, in turn, helps prevent the deterioration of a managed CPR.

A substantial volume of literature has amassed concerning the usefulness and validity of Ostom's (1990) design principles, and the reactions have been mixed. Although there has been substantial support for the principles, some scholars have criticized their theoretical grounding or argued that they are overly precise with respect to the range of conditions to which they might be applied. Given that much has been written about the design principles since 1990, it seems appropriate now to conduct a review of the relevant literature to document its findings and re-evaluate the principles.

\section{METHODS}

\section{Data collection and coding}

We examined studies that evaluated Ostom's (1990) design principles directly or indirectly in the context of communities that use common-property arrangements to manage CPRs. A study is a journal article, book, or other work that we coded for the purposes of analysis. We used two data sets: the study data set, which we discuss first; and the case data set, which we discuss second.

Two methods were used to populate the study data set. The first method involved conducting searches in standard academic databases and relevant journals, as well as in the library at the Workshop in Political Theory and Policy Analysis at Indiana University. This library is a special collection created to form a thorough representation of writings on the commons. It includes the Digital Library of the Commons, which is an online repository of full-text articles, books, book chapters, conference papers, theses, dissertations, and working papers (http://dlc.dlib.indiana.edu/). The second method involved a snowball procedure wherein studies analyzed in the first step were used to find other studies that referenced them or were referenced by them and were considered relevant to the project.

Only studies published subsequent to Ostrom's (1990) book were considered. Many of the studies analyzed are mentioned later in this analysis for demonstrative purposes. The full list of studies that we coded is available as an appendix to the Digital Library of the Commons website (http://hdl.handle. net/10535/6613). Following data collection, we looked for patterns in the studies by coding relevant variables for each study and entering them into a common database. Some of the primary fields coded included: methodology, sector, evaluation, and overt.

\section{Methodology}

We first divided the studies into four methodological types that indicated whether the study was a relatively detailed case study, a statistical study, a synthesis study, or an abstract study. The first three methodological types are empirical studies, whereas the fourth type is not. The following descriptions were used as a guide in determining the type of each study. A detailed study 
contained a detailed description of one or more cases of community-based CPR management. Detailed studies included single and comparative case studies and in-depth meta-analyses of cases conducted by others. A statistical study contained a statistical analysis of many cases without exploring their individual properties in depth. A synthesis study combined findings from two or more cases, but did not contain the detail needed to produce casespecific conclusions regarding the design principles. An abstract study contained a primarily abstract or theoretical argument, with only anecdotal references to cases or empirical data.

\section{Sector}

We then divided the studies into sectors based on what type of CPR was being managed: forest, fishery, irrigation, pasture, multiple, or other. Studies that were coded as multiple did not focus exclusively on one of these four sectors, but rather examined combinations of some or all of the sectors. Studies that were coded as other examined a different resource altogether.

\section{Evaluation}

The evaluation variable is an important outcome variable in our analysis. It indicates the general level of support that a study shows for the design principles and ranges from one to five, with one being highly unsupportive and five being highly supportive. For empirical studies, the coding was based on the balance of positive and negative evidence presented in the study. If there was positive evidence and no negative evidence, or if there was overwhelming positive evidence and little negative in an empirical study, it was coded as highly supportive. If there was moderately positive evidence that outweighed some negative evidence, or slightly positive evidence and no negative evidence, the study was coded as moderately supportive. If there was an equal mix of positive and negative evidence, the study was coded as neutral. Coding moderately to highly unsupportive studies followed criteria that were analogous to the supportive categories.

Coding the evaluation field for studies that did not have empirical data was more impressionistic. For abstract studies, we had to interpret the degree to which the author favored or criticized specific principles or the design principles approach. In recognition of the possibility for bias in the coding of an impressionistic variable, the field was coded by two separate coders for each study. Where there was disagreement between the two coders, we opted for the more conservative (lower) value.

Finally, for both empirically grounded and abstract studies, if our impressions of the data presented disagreed with the author's own interpretations or descriptions, we always coded according to the author's inferences, rather than our own impressions. This procedure helped to protect against possible bias in coding the studies.

\section{Overt}

The overt field indicated whether a study explicitly or implicitly evaluated the design principles.

\section{Coding of cases}

A detailed study may contain more than one case. A case is an empirical work focusing on a particular geographic area that contains one or more communities that manage a single CPR or a set of closely related CPRs, and which evaluates Ostrom's (1990) design principles explicitly or implicitly. Cases were coded separately in the case data set. If a study described a number of cases but only discussed them anecdotally to produce its conclusions, or if it described a whole set of cases as one type of case, it was coded as a synthesis and not a detailed case study, and the cases mentioned were not included in the case data set. Likewise, observations from statistical studies were not included as cases in our analysis. A detailed study could contain two cases of the same set of communities and CPR if they were presented during substantially different time periods and important changes had taken place between the periods. A common example of this is an account of a historically successful case that in more recent times has been struggling to deal with novel socioeconomic disturbances (e.g., timber markets). For such an example, there could be a historical case and a modern case for the same community or set of communities managing a CPR.

The most important variables coded for each of the cases were the success and evidence variables, each is of which is binary. The success variable was coded as one if a case reported successful long-term environmental management and zero if it reported a clear failure in collective action and management. If the author was ambiguous, offered multiple 
conflicting outcomes, or offered an outcome irrelevant to the collective action theory of the design principles, the success field was left blank.

We coded an evidence variable for each of the design principles for each case. This variable indicated whether we could infer from the evidence that conditions satisfying each principle were present in a case. If there was evidence of satisfying conditions, we coded a one for that case. If there was positive evidence against such conditions, we coded a zero. If no reference was made to the principle, or if we considered the description overly ambiguous, we left the field blank for that principle and considered it a missing datum. As a result of this method of coding, many of the cases have no entries for several of the principles, and each principle is essentially associated with its own subset of cases in the data set.

Unlike the evaluation variable for the studies, we did not double-code the important variables for every case because, for many, the authors itemized their discussion of each principle and overtly stated its presence and/or importance. Similarly to the coding of studies, we coded according to the authors' own statements, rather than our impressions, if there was a conflict between the two. Depending on how ambiguous a case was in its description, more or less discussion among the coders took place to determine what coding, if any, was warranted.

A total of 91 studies and 77 cases were coded.

\section{Analytical methods}

We applied two levels of quantitative analysis to these data once they were coded. The first was a statistical description of the level of support found in the studies based on the evaluation variable. We examined the interactions between an ordinal dependent variable that ranged from one to five (the evaluation variable) and several categorical variables (the various types of studies). We used descriptive tables and two statistical tests: the Mann-Whitney test to explore possible differences in the evaluation scores between any two study categories, and the Kruskal-Wallis test to look for significant differences between a set of study categories.
Following this, we evaluated the importance of the individual design principles as they were coded in the cases. Because most of the cases did not give enough information to code the importance of all of the principles, we analyzed these data on a principle basis, rather than attempting to combine the data into one larger analysis, which would suffer from a large missing-data problem. Thus, we conducted a separate analysis for each design principle.

For each principle, we explored the joint distribution of the evidence and success variables of the cases that recorded values of each variable for that principle. These distributions gave us an idea of whether the presence of conditions related to a particular principle is positively associated with a case reporting successful long-term CPR management. We used Fisher's exact test to determine whether the evidence variable was independent from the success variable. This test is more appropriate for $2 \times 2$ tables with smaller sample sizes than those analyzed using the common Chi-square test (Field 2009). We then reported the proportion of supportive cases to unsupportive cases for each principle. Finally, we calculated an effect size between the two variables using the phi statistic, which is an appropriate measure of the strength of correlation between two dichotomous variables (Field 2009).

\section{RESULTS}

The overall average of the evaluation variable across all 91 studies was 3.73, or slightly below the value for moderately supportive (Table 1 ). There was a significant difference among the levels of support for the design principles across the methodological study types (Kruskal-Wallis test; $P$ $=0.004)$. There were more detailed studies and syntheses than other study types, and they tended to have the highest evaluation values. Statistical studies were somewhat lower in their evaluations, but were still supportive. Abstract studies had a median evaluation score of 2.0 , or moderately unsupportive. The difference between the evaluation value of the abstract studies and the three types of empirical studies as one group was statistically significant (Mann-Whitney test; $P=$ 0.002). Moreover, when abstract studies were excluded from the analysis, the differences among the other three categories became nonsignificant (Kruskal-Wallis test; $P=0.122$ ). This indicates that 
much of the criticism or lack of support directed at the principles in the literature that we reviewed was of an abstract, rather than an empirical, nature.

We also analyzed several other relationships. When we analyzed the evaluation variable by study sector, each sector was at least somewhat supportive of the design principles (Table 2), and the differences among the categories was not statistically significant (Kruskal-Wallis test; $P=0.747$ ). Similarly, the medians were consistent across all categories. The slightly lower mean values for the pastoral and other categories resulted primarily from a single study in each group that had an evaluation value of one (highly unsupportive). The value of the multiple category likewise contained two such highly unsupportive studies that lowered its mean. Without these critical studies, the mean for each of these groups would have been four, or moderately supportive. Thus, we conclude that there was not much difference among sectors in the level of support for the principles.

Subsequently, we tested and found no statistical relationship between the evaluation score of a study and the year in which it was published or produced. Finally, we analyzed whether studies that overtly evaluated the principles were more or less supportive than studies that only evaluated them implicitly, without mentioning the principles. Of the 91 studies, 60 were overt and 31 were not. The mean evaluation score for the overt studies was 3.60, whereas the mean for studies that did not directly evaluate the principles was 3.97, and the median for both categories was 4.0; the difference was not statistically significant $(P=0.343)$. Moreover, we attribute much of the difference between the means to the fact that all nine abstract (and generally unsupportive) studies were overt. If we take these nine abstract studies out of the overt group, the average evaluation value for empirical studies that overtly evaluated the design principles rises to 3.82 . The difference remains statistically nonsignificant $(P=0.842)$.

We then looked at the importance of the individual design principles in the coded cases. We used a slightly modified version of the design principles to code the studies. Ostrom initially constructed eight principles. For coding purposes, we divided principles 1, 2, and 4 into subcomponents labeled $1 \mathrm{~A}$ and $1 \mathrm{~B}$ and so forth, so that we could analyze the importance of these subcomponents individually (Table 3).
For each principle, we examined the joint distribution of the evidence and success variables for the cases that recorded each variable for that principle (Table 3 ). The evidence variable indicates whether conditions satisfying a principle are present in the case, whereas the success variable indicates whether the case reports successful communitybased natural resource management. Combinations in which the evidence and success variables have equal values (both one or both zero) are supportive of the design principles theory. For example, the upper left cell for principle 1A indicates that 31 cases were coded as indicating successful management as well as the presence of user boundaries; these cases are supportive of principle 1A. These supportive combinations are in the main diagonal of each of the cross-tabulations. The two other combinations in the off-diagonals are unsupportive. With more cases in each main diagonal than in the corresponding off-diagonal, these joint distributions show that each principle has more supportive than unsupportive cases.

Fisher's exact test between the evidence and success variables produced probabilities that were significant at the $5 \%$ level for every principle except Principle 8, which was significant at the $10 \%$ level (Table 3). Therefore, we generally reject the null hypothesis that the two variables are independent for each principle. The principles varied widely in their ratios of supportive to unsupportive cases, but every one had at least twice as many supportive cases as unsupportive. In our following discussion of the design principles, we refer to principles with ratios $>10$ as very strongly supported, ratios of 510 as strongly supported, and ratios of 2 to $<5$ as moderately well supported. Finally, the phi statistic measures the strength of an association between two dichotomous variables and is similar to a correlation coefficient in interpretation. A value of zero for this statistic indicates little to no association between two dichotomous variables, whereas a value of one indicates a very strong positive association. All of the associations between the two variables are positive.

\section{DISCUSSION}

Here, we discuss each of the design principles qualitatively to address particular issues that arose, or important critiques that we found. 
Table 1. Mean and median ranking of the evaluation of the design principles for each methodological type of study.

\begin{tabular}{lccc}
\hline \hline Study type & $N$ & Mean & Median \\
\hline Detailed & 46 & 3.85 & 4.0 \\
Statistical & 8 & 3.50 & 3.5 \\
Synthetic & 28 & 4.04 & 4.0 \\
Abstract & 9 & 2.33 & 2.0 \\
Total/all types & 91 & 3.73 & 4.0 \\
\hline
\end{tabular}

\section{Eight principles}

\section{Principle 1: Well-defined boundaries}

This principle, as Agrawal (2002) notes, originally stipulated the presence of well-defined boundaries around a community of users and boundaries around the resource system this community uses. Each component helps to internalize the positive and negative externalities produced by participants, so they bear the costs of appropriation and receive some of the benefits of resource provision. Each component was coded separately, with community boundaries coded as principle $1 \mathrm{~A}$ and resource boundaries coded as 1B (Table 3 ). There was strong evidence for $1 \mathrm{~A}$ and moderate evidence for $1 \mathrm{~B}$. Pinkerton and Weinstein (1995:25), for example, state, "Exclusion of outsiders from fishing space was the main mechanism used by the villagers to control fishing effort. This is one of the most common and universal mechanisms found in community-managed inshore fisheries."

This principle was also the most frequent target of (primarily theoretical) criticisms. The main complaints concerning this principle are that it is too rigid and that, in many systems, fuzzier social or geographic boundaries are needed to facilitate more flexible, ad hoc arrangements between participants (Ruddle 1996, Cleaver 1999, 2000, Turner 1999, Mandondo 2001, Blaikie 2006). Cleaver (1999:603) states, "A concentration on boundaries highlights the need in development for clear administrative arrangements, more to do with the delivery of goods and facilities than a reflection of any social arrangement." Likewise, Turner (1999:649) states, "Practitioners tend to expect the 'community' to be an immutable group of people jointly managing a delimited common resource through uncontested, clearly defined rules of access. Agro-pastoral reality strongly diverges from this model. Rules of access are often politically malleable and spatial boundaries fluid." Finally, Ruddle (1996) emphasizes that boundaries may have a gradient quality to them, with the strength of access rights of a particular group to a CPR gradually diminishing or increasing across a certain distance.

Several critics who favor a looser conception of geographic boundaries note, however, that they do not mean that the resource should be open access or entirely boundary free, but merely that boundaries should be more fluid than they think Ostrom (1990) conceptualizes them (e.g., Turner 1999). NiamirFuller (1998) gives an example of how such a system of fluid boundaries can persist, describing how the boundaries between different groups of pastoralists in Sahelian Africa are fuzzy and contain overlapping, jointly managed zones and areas to which access is negotiated ad hoc among interested parties.

\section{Principle 2: Congruence between appropriation and provision rules and local conditions}

Ostrom's (1990:92) second design principle refers to the "congruence between appropriation and provision rules and local conditions." Like the first principle, this principle stipulates two separate 
Table 2. Mean and median ranking of the evaluation of the design principles for each resource sector analyzed.

\begin{tabular}{lccc}
\hline \hline Sector & $N$ & Mean & Median \\
\hline Forestry & 27 & 3.67 & 4.0 \\
Pastoral & 6 & 3.50 & 4.0 \\
Irrigation & 24 & 3.92 & 4.0 \\
Fishery & 17 & 3.88 & 4.0 \\
Multiple & 12 & 3.50 & 4.0 \\
Other & 5 & 3.40 & 4.0 \\
Total/all sectors & 91 & 3.73 & 4.0 \\
\hline
\end{tabular}

conditions that Agrawal (2002) recognizes. The first condition is that both appropriation and provision rules conform in some way to local conditions; Ostrom emphasizes local conditions of the CPR, such as its spatial and temporal heterogeneity. The second condition is that congruence exists between appropriation and provision rules. We found very strong empirical evidence for both principles.

Regarding principle $2 \mathrm{~A}$ and the congruence between rules and local conditions (Table 3), the literature predominately reflects Ostrom's emphasis on an institutional congruence with the resource condition, in line with the Spanish irrigation case she discusses. For example, Guillet (1992:104) describes practices in Peruvian irrigation systems: "Under normal conditions farmers are given water sufficient to cover the requirements of their fields, a proportional allocation with Inka antecedents... when water scarcity threatens, this principle is modified and actions are taken to ensure that each household has access to a subsistence minimum."

Some scholars have also identified local conditions as involving the predominant culture, ideology, customs, and livelihood strategies of a community (Morrow and Hull 1996, Young 2002, Gautam and Shivakoti 2005). Other authors have highlighted the negative consequences that result when externally imposed rules do not match local customs and livelihood strategies. For example, Gautam and Shivakoti (2005) observed that the rules designed by the Dhulikhel municipality imposed a total ban on the harvest of forest products and that these rules did not match the resource conditions and contradicted customary rules of villagers, who had traditionally allowed activities such as the collection of leaf litter for animal bedding and fallen twigs for firewood. In turn, the effectiveness of monitoring and compliance with rules was very low, and the forest had come under high extraction pressure. Morrow and Hull (1996) studied a donor-initiated forestry cooperative in the Palcazu Valley of Peru and came to similar conclusions regarding the need for this internal-external type of congruency.

Turning to principle 2B (Table 3), congruence between appropriation and provision rules is frequently described in the literature as congruence between costs incurred by users and the benefits they receive via their participation in collective action. Pomeroy et al. (2001:4) echo Ostrom's finding, stating that in successful systems, "individuals have an expectation that the benefits to be derived from participation in and compliance with community-based management will exceed the costs of investments in such activities." Similarly, Klooster (2000) compared seven communities that have been successful in managing logging activities and found that a common feature in these communities is their effort to fairly reinvest benefits into the community by paying for reforestation work and providing public goods such as road maintenance. 
Table 3. Relationship between each design principle and success or failure in the cases analyzed.

\begin{tabular}{|c|c|c|c|c|c|c|c|}
\hline \multirow[b]{2}{*}{ Design principle $\dagger$} & \multirow[b]{2}{*}{ Support } & \multicolumn{2}{|c|}{ Evidence } & \multirow[b]{2}{*}{$N$} & \multirow[b]{2}{*}{$P \ddagger$} & \multirow[b]{2}{*}{ Ratioß } & \multirow[b]{2}{*}{$\begin{array}{l}\text { Effect } \\
\text { size }\end{array}$} \\
\hline & & 1 & 0 & & & & \\
\hline \multirow{2}{*}{$\begin{array}{l}\text { 1A. Clearly defined boundaries: Individuals or households who have rights } \\
\text { to withdraw resource units from the common-pool resource (CPR) must be } \\
\text { clearly defined. }\end{array}$} & Success & 31 & 2 & 63 & $<0.0001$ & 5.3 & 0.692 \\
\hline & Failure & 8 & 22 & & & & \\
\hline \multirow{2}{*}{$\begin{array}{l}\text { 1B. Clearly defined boundaries: The boundaries of the CPR must be well } \\
\text { defined. }\end{array}$} & Success & 22 & 4 & 42 & 0.049 & 2.2 & 0.313 \\
\hline & Failure & 9 & 7 & & & & \\
\hline \multirow{2}{*}{$\begin{array}{l}\text { 2A. Congruence between appropriation and provision rules and local } \\
\text { conditions: Appropriation rules restricting time, place, technology, and/or } \\
\text { quantity of resource units are related to local conditions. }\end{array}$} & Success & 20 & 0 & 30 & 0.001 & 5.0 & 0.737 \\
\hline & Failure & 5 & 5 & & & & \\
\hline \multirow{2}{*}{$\begin{array}{l}\text { 2B. Congruence between appropriation and provision rules and local } \\
\text { conditions: The benefits obtained by users from a CPR, as determined by } \\
\text { appropriation rules, are proportional to the amount of inputs required in the } \\
\text { form of labor, material, or money, as determined by provision rules. }\end{array}$} & Success & 11 & 1 & 22 & 0.002 & 10.0 & 0.632 \\
\hline & Failure & 1 & 9 & & & & \\
\hline \multirow{2}{*}{$\begin{array}{l}\text { 3. Collective-choice arrangements: Most individuals affected by the } \\
\text { operational rules can participate in modifying the operational rules. }\end{array}$} & Success & 20 & 6 & 49 & 0.001 & 2.8 & 0.466 \\
\hline & Failure & 7 & 16 & & & & \\
\hline \multirow{2}{*}{$\begin{array}{l}\text { 4A. Monitoring: Monitors are present and actively audit CPR conditions } \\
\text { and appropriator behavior. }\end{array}$} & Success & 32 & 3 & 63 & $<0.0001$ & 3.8 & 0.587 \\
\hline & Failure & 10 & 18 & & & & \\
\hline \multirow[t]{2}{*}{ 4B. Monitoring: Monitors are accountable to or are the appropriators. } & Success & 27 & 2 & 38 & $<0.0001$ & 11.7 & 0.792 \\
\hline & Failure & 1 & 8 & & & & \\
\hline \multirow{2}{*}{$\begin{array}{l}\text { 5. Graduated sanctions: Appropriators who violate operational rules are } \\
\text { likely to be assessed graduated sanctions (depending on the seriousness and } \\
\text { context of the offense) by other appropriators, officials accountable to these } \\
\text { appropriators, or both. }\end{array}$} & Success & 13 & 4 & 36 & 0.019 & 2.3 & 0.398 \\
\hline & Failure & 7 & 12 & & & & \\
\hline \multirow{2}{*}{$\begin{array}{l}\text { 6. Conflict-resolution mechanisms: Appropriators and their officials have } \\
\text { rapid access to low-cost local arenas to resolve conflicts among } \\
\text { appropriators or between appropriators and officials. }\end{array}$} & Success & 26 & 2 & 42 & 0.01 & 3.2 & 0.429 \\
\hline & Failure & 8 & 6 & & & & \\
\hline \multirow{2}{*}{$\begin{array}{l}\text { 7. Minimal recognition of rights to organize: The rights of appropriators to } \\
\text { devise their own institutions are not challenged by external governmental } \\
\text { authorities. }\end{array}$} & Success & 28 & 3 & 51 & 0.032 & 2.2 & 0.311 \\
\hline & Failure & 13 & 7 & & & & \\
\hline \multirow{2}{*}{$\begin{array}{l}\text { 8. Nested enterprises: Appropriation, provision, monitoring, enforcement, } \\
\text { conflict resolution, and governance activities are organized in multiple } \\
\text { layers of nested enterprises. }\end{array}$} & Success & 27 & 4 & 51 & 0.065 & 2.0 & 0.262 \\
\hline & Failure & 13 & 7 & & & & \\
\hline
\end{tabular}

$\dagger$ The language used to describe each principle follows that of Ostrom (1990:90). $\ddagger$ Significance of Fisher's exact test between the evidence and success variables. $\S$ The number of supportive cases (main diagonal) to unsupportive cases (off-diagonal). |The effect size was determined using the phi statistic, which is similar in interpretation to a beta coefficient in a standard regression. 
Additionally, some scholars have pointed to the importance of users perceiving the match between appropriation and provision rules as fair, relating this condition to a principle of equity found in the literature. In the Andean irrigation system of Huayncotas, for example, all farmers have to contribute to maintenance of the system, but they do it in proportion to the amount of land each of them irrigates (Trawick 2001). Trawick (2001) found that the fact that appropriation and provision rules are applied to everybody while varying with each farmer's needs reinforced a commonly shared sense of equity and facilitated the sustainability of the management system. Cox (2010) observed a similar feature in the acequia irrigation systems in the Taos Valley, New Mexico. In times of plenty, the acequias apportion water to members in accordance to the amount of land owned, which is in turn proportional to members' provision obligations. In times of scarcity, this principle is altered to assure that each member has enough to survive. This system is in fact a combination of principles $2 \mathrm{~A}$ and $2 \mathrm{~B}$ and is an example showing that what is considered equitable may vary depending on how much of a resource is available.

\section{Principle 3: Collective-choice arrangements}

Regarding principle 3, Ostrom (1990:90) states, "most individuals affected by the operational rules can participate in modifying the operational rules." This principle is in the spirit of a large amount of literature on the importance of local knowledge in natural resource management (e.g., Berkes et al. 2000), in which local users have first-hand and lowcost access to information about their situation and thus a comparative advantage in devising effective rules and strategies for that location, particularly when local conditions change.

This principle was moderately well supported. Sarker and Itoh (2001:19), for example, examined the successful Nishikanbara Land Improvement District in Japan and found that terminal water user groups within the district "collectively participate in modifying their daily operational rules." A lack of a functional collective-choice arrangement is frequently correlated with CPR management failure. For example, in discussing the management of communal grazing land in rural Tanzania, Nilsson (2001) describes a failure case wherein residents of Endabeg Village were members of the decision-making village assembly, but the assembly was ineffective as a local decision-making organization. Other venues for collective management, although present, were also weak.

Some scholars who have critiqued this principle do not argue that it would lead to negative results if properly implemented. Rather, they are concerned with situations wherein the principle exists in form but in practice has been co-opted or undermined by locally powerful or external bureaucratic actors (Cleaver 1999, Skjølsvold 2008). The concern is similar to that expressed by others for principle 1A: the critical feature might result from an administrative or bureaucratic imposition, or it might ignore some important features of the local context.

\section{Principle 4: Monitoring}

Like principles 1 and 2, we treated principle 4 as two subcomponents. Principle 4A stipulates the presence of monitors, whereas $4 \mathrm{~B}$ stipulates the condition that these monitors are members of the community or otherwise accountable to those members. Monitoring makes those who do not comply with rules visible to the community, which facilitates the effectiveness of rule enforcement mechanisms and informs strategic and contingent behavior of those who do comply with rules. Empirically, principle 4A was moderately well supported, whereas 4B was very strongly supported by the case data.

In many cases, monitoring is a byproduct of particular ways of managing the commons, and the costs of monitoring are kept low (Schmidtz and Willott 2003). Ostrom (1990) noted this possibility in her original study. Trawick (2001) echoes Ostrom's example in his analysis of a community irrigation system in Peru, in which the farmers developed a contiguous pattern for irrigating one section of the system at a time before moving to other sections. This system was effective at conserving water, but it also made irrigation a public affair and facilitated effective decentralized monitoring. This pattern also occurs in the acequia irrigation systems in New Mexico (Cox 2010).

In other cases, monitors constitute a separate position that is compensated. Agrawal and Yadama (1997:455) studied the strength of local forest institutions in Kumaon Himalaya, India, and found that "the number of months a guard was hired has a very strong and statistically highly significant direct effect on forest condition." Likewise, 
Bardhan (2000) performed a statistical analysis of 48 irrigation systems and found a positive correlation between cooperative behavior and the presence of a guard position. However, Agrawal and Chhatre (2006) found a negative correlation between the presence of a guard and forest conditions in their statistical analysis of 95 community-based forest management systems in India. They interpret this result as follows. "In the studied cases, villagers are more likely to hire guards and impose fines more frequently if their forests are not in a good condition in an effort to improve their forests. Thus, the causal arrow suggested by our data runs in the reverse direction from what we had hypothesized" (Agrawal and Chhatre 2006:160). As these examples indicate, conditions regarding monitoring were prominent in the statistical studies.

Monitors may not perform satisfactorily if they do not directly benefit from improved resource conditions. Thus, it may be important that monitors are accountable to those who most depend on the resource. Gautam and Shivakoti (2005), who studied two forest systems located in the Middle Hills of Nepal, found that the ability of local users to oversee monitors' performance affected resource conditions. In Jylachitti Forest, local users hired two people for regular monitoring and paid them through contributions from each member household. In Dhulkhel Forest, guards were also hired, but they were paid by local authorities. Whereas Jylachitti local users were engaged in supervising the guards' performance in controlling timber extraction levels, this was not the case in Dhulkhel, where overextraction was becoming an issue by the end of the study.

Scholars have also pointed to the importance of environmental monitoring, that is, the acquisition of information about the conditions of the appropriated CPR (Pinkerton and Weinstein 1995, Cinner et al. 2009). With environmental information, community members can elaborate and adapt appropriation and provision rules that help to guarantee the sustainability of the resource (López Gunn and Hernandez Mora 2001, Young 2002, Johnson and Nelson 2004, Sandström and Widmark 2007). López Gunn and Hernandez Mora (2001) studied three groundwater irrigation systems and found that an irrigation community whose members were engaged in environmental monitoring enjoyed higher levels of information sharing and collective preparedness than a community that depended on the information provided by multiple external authorities. Pinkerton and Weinstein (1995) compared four U.S. oyster fisheries and found that the two cases that used stock assessment processes appeared to be more sustainable.

\section{Principle 5: Graduated sanctions}

Principle 5 stipulates the efficacy of graduated sanctioning systems. Sanctioning deters participants from excessive violations of community rules. Graduated sanctions progress incrementally based on either the severity or the repetition of violations. Graduated sanctions help to maintain community cohesion while genuinely punishing severe cases; they also maintain proportionality between the severity of violations and sanctions, similar to the proportionality between appropriation and provision rules from principle 2 .

Principle 5 was moderately well supported. Ghate and Nagendra (2005), for example, describe the failure of efficacious forest management in two communities in Maharashtra, India, relative to successful management in a third. Although graduated sanctions formally existed in all three communities, only the successful community had a strictly implemented, graduated penalty structure.

There was a small subset of the literature that questioned principle 5 by arguing that sanctions are not needed in the presence of strong social capital and should not be implemented as a replacement for it. Cleaver (2000:374) describes such a situation in her account of water management practices in the Nkayi District in western Zimbabwe. There is a similarity here with the concerns expressed for principles $1 \mathrm{~A}$ and $1 \mathrm{~B}$ that the design principles abstract too much from local context, which, in this case, is the web of relationships in which actors are embedded.

We have already seen that people prefer to spend more time negotiating consensus than establishing and imposing sanctions. Solidarity in this case cannot simply be interpreted functionally as being directly about cooperation over the mechanisms of water resource management. It is comprised of complex networks of cooperation based on family structure, labour-sharing arrangements and numerous interrelated associational activities such as church groups, savings clubs, and income- 
generating groups. The village apparently most successful at collective action regarding water supplies was also remarkable for its other cooperative activities, for its success in agricultural production and for the frequency and cheerful creativity of its public social occasions. Cleaver (2000:374).

\section{Principle 6: Conflict-resolution mechanisms}

Principle 6 states that systems with low-cost conflict resolution mechanisms are more likely to survive. Conflict over an exhaustible resource is inevitable in CPR management, necessitating the presence of established mechanisms for conflict resolution to maintain collective action. This principle was moderately well supported by the empirical data. In the acequia irrigation communities in northern $\mathrm{New}$ Mexico, for example, there is a long history of recourse to external court systems under different national regimes to resolve intercommunity conflicts. Several agreements reached by territorial probate courts more than 100 years ago are the basis for functioning, modern water-sharing agreements today (Cox 2010).

When conflict resolution mechanisms are not available or easily accessible, successful CPR management appears more difficult. One example of this comes from several user groups of Chilika Lake in Orissa, India (S. P. Rout, unpublished manuscript: http://dlc.dlib.indiana.edu/dlc/bitstream/ handle/10535/2073/Shyama Prasad.pdf?sequence $=1$ ). In the 1990s, the management of this resource system was proving to be very problematic. Nonfishers began to compete with traditional cultural fishing communities over access and resource use, leading to major conflict and unrest and, in 1999, violence that resulted in the shooting of four community members. Although the national government subsequently stepped in to mediate, Rout (unpublished manuscript) notes that this mechanism for conflict resolution has not yet proven itself viable.

\section{Principle 7: Minimum recognition of rights}

Principle 7 stipulates that external government agencies do not challenge the right of local users to create their own institutions. An external government agency imposing its own rules on a community managing a CPR may suffer from a government failure of the kind discussed by Hayek
(1945) and Scott (1998) if the externally imposed rules do not correspond to local conditions.

The empirical evidence for this principle was moderately supportive. Pagdee et al. (2006), in their analysis of 69 case studies of forest management worldwide, found that local authority was associated with tenure security, a key element for sustainable forest management. There is also evidence in the studies that violations of this principle can be associated with less successful community-based resource management regimes. Community-based resource management projects developed in Sudano-Sahelian West Africa in the 1990s, which involved the devolution of resource management authority to rural communities through the assistance of nongovernmental organizations, failed in part by not recognizing local knowledge and existing institutions at the early stages of the devolution process (Turner 1999).

\section{Principle 8: Nested enterprises}

Principle 8 states that in successful systems, "governance activities are organized in multiple layers of nested enterprises" (Ostrom 1990:90). As for principle 7 , which also deals with cross-scale institutional factors, the empirical evidence for principle 8 was moderately supportive.

Many scholars, particularly those focusing on pastoral and irrigation systems, have stressed the importance of nesting smaller common-property systems in larger and still larger ones, given the high probability that the social systems have cross-scale physical relationships when they manage different parts of a larger resource system and thus may need mechanisms to facilitate cross-scale cooperation (Lane and Scoones 1993, Niamir-Fuller 1998). Part of the motivation for this principle, then, relates to principle 1 (user and resource boundaries) and is stated by Hanna et al. (1995:20) as: "It is important to ensure that a property rights regime has clearly defined boundaries, and that to the extent possible, those boundaries are consistent with the natural boundaries of the ecological system." It is not just user and resource boundaries that are important; a match between these boundaries may be important as well, and institutional nesting is an important way to accomplish this in many situations.

One additional clarification regarding principle 8 is that the nesting may occur either between user groups and larger governmental jurisdictions, or 
between user groups themselves. Many traditional irrigation systems, for example, contain multiple levels of organization that mirror the branching properties of an irrigation system (Coward 1977). This is somewhat different from co-management arrangements between user groups and a larger government body, described in extensive publications (Berkes and Folke 1998, Berkes 2002, Yandle 2006, Cinner et al. 2009). Intercommunity connections can be thought of as horizontal linkages, whereas connections between multiple jurisdictional levels can be thought of as vertical linkages. It is our understanding that, when she formulated this principle, Ostrom (1990) was referring to vertical linkages. We would generalize principle 8 to include both horizontal and vertical linkages because they may accomplish similar functions.

\section{Critique of the principles}

We identified three primary critiques directed at the design principles as a whole. First, some of the publications argue that the design principles are incomplete, and many studies suggest additional criteria for sustainable management. Some scholars argue that critical social variables need to be included in a full account of successful communitybased natural resource management. Singleton and Taylor (1992), for example, argue that the more fundamental feature of the successful systems in Ostrom's (1990) study is the quality that each involves a "community of mutually vulnerable actors." In Singleton and Taylor's (1992) view, these conditions explain why some communities are able to fulfill the design principles and sustain themselves while others are not. In another example, Harkes (2006:250-251), who studied marine sasi fishery systems in Indonesia, states:

\footnotetext{
The design principles of Ostrom (1990) and other scientists who have pursued this line of thinking thus are an interesting point of exit, but only partly explain the success of management institutions. Most of the conditions mentioned are merely characteristics of the community or institution, such as scale, village size, homogeneity, or the ability to exclude outsiders, and even though these factors undoubtedly contribute to their functionality, from our study it has become clear that the real 'glue' that keeps an institution alive over time are the social
}

mechanisms, i.e., trust, legitimacy, and transparency.

Other scholars argue for including the relevant properties of the resource system itself in more detail (Schlager et al. 1994, Agrawal 2002, Young 2002, Agrawal and Chhatre 2006, Tucker et al. 2007). Young (2002) argues that more sophisticated treatment of ecosystem properties and structures should be incorporated into a diagnostic analytical approach that seeks to match institutional arrangements to those properties and structures. Ostrom (2007) takes a similar direction in formulating a framework that contains many types of resource properties across multiple scales. These two works are highly relevant to the third critique, which we discuss later.

Besides local biophysical properties, much of the literature stresses the importance of external factors that are not stressed in the design principles (Johnson 1997, Steins and Edwards 1999, Bardhan 2000, Agrawal 2002; N. A. Steins, N. G. Röling, and V. M. Edwards, unpublished manuscript: http: //dlc.dlib.indiana.edu/dlc/bitstream/handle/10535/507/ steinsn052400.pdf?sequence=1). External socioeconomic factors are particularly emphasized. Tucker (1999) and Tucker et al. (2007) stress that market integration can lead to rising inequality or declining resource (forest) conditions. Bardhan (2000:861) finds that "cooperative behavior in an irrigation community is by and large significantly related negatively to... urban or market connections." Some authors such as Klooster (2000) argue that development and market forces can destabilize CPR arrangements that worked well when the community and resource were isolated. In an analysis of factors affecting overfishing in smallscale coral reef fisheries in Papua New Guinea, Cinner and McClanahan (2006:78) find suggestive statistical evidence that "communities in close proximity to markets had likely overfished the higher value and high trophic level species."

Market integration may effectively remove control of a resource from a user group. Another mechanism that seems to be functioning in some of these situations is that external integration alters local incentives, frequently by decreasing the dependence of local users on the resource. Pinkerton and Weinstein (1995) and Gibson (2001) note that dependence on the resource used by a community is an important factor in the robustness of the management regime. When members are not as 
dependent on the resource, their welfare is not as strongly tied to their cooperative behavior.

In our view, the critique that the design principles are incomplete is sound. There are several other important features of relevant systems that affect outcomes when CPRs are managed by communities of users. In an increasingly interconnected world, it is hard to argue that we should only consider locallevel institutional properties. Local and external socioeconomic factors need to be considered as well. At the same time, we do not think that this critique undercuts the empirical support for the principles indicated by our quantitative analysis. To some extent, exploring socioeconomic or biophysical factors is an analysis that is distinct from the one considered here, and empirical evaluations of the two are likewise distinct.

The second main issue raised regarding the design principles is whether they can be applied to a wide range of cases beyond those that were used to develop them. Several authors (Pomeroy et al. 2001, Young 2002, Berkes 2005, 2006) question the applicability of the principles to cases larger in scale than those from which Ostrom (1990) derived them. Berkes (2005:19), for example, states, "Globalization has a major impact on local-level resource management through such mechanisms as the creation of international markets. Can a theory of the commons, based on local-level cases, be scaled up to deal with the complexity of communities and social-political networks?" Young (2002) argues that this is unlikely to be the case.

We cannot offer an empirical answer to this critique because we did not formally analyze large, noncommunity-based systems. Nevertheless, it seems plausible that several of the principles would be applicable to higher levels of governance (Rowland 2005). Proportionality of costs and benefits, conflict-resolution mechanisms, nested institutional arrangements, and effective and participatory collective-choice arrangements seem particularly relevant. The applicability of the design principles to a higher level of governance is not a claim that communities can necessarily resolve large-scale environmental problems. The comanagement literature (Berkes 2002) makes a strong case that, by themselves, they likely cannot.

The final critique criticizes what it conceives as the design principle approach itself. Several authors argue for a more constructionist or historically, socially, and environmentally embedded perspective that departs from viewing actors as rational decision makers, and communities of users as coherent wholes without internal conflict or heterogeneity (Mosse 1997, Leach et al. 1999, Klooster 2000). Others authors suggest that the design principles are biased toward formal rules and strategies and may abstract too much from the complexity of the environment and the social context of the actors (Cleaver 1999, 2000, Steins 1999, Steins and Edwards 1999, Blaikie 2006).

Related to these arguments is the general concern that the principles might be seen as something of a magic bullet or institutional panacea and thus be misapplied as a prescription for improving the governance of CPRs in particular settings (Bruns 2007). This concern is over the possible overgeneralization the principles to a large diversity of cases, the individuality of which they do not sufficiently reflect. This issue of theoretical generalizability and the tension between it and theoretical precision is too large to treat adequately here. Cox (2008) describes the trade-off between generalizability and precision that Ostrom (1990) made in her formulation of the principles.

A concern about implementing a set of possibly overgeneralized design principles is analogous to that raised by Hayek (1945) and Scott (1998): that a government may fail by homogenizing the diversity of contexts to which it applies its policies and management practices. This is sometimes referred to as a blueprint approach to governance, which leads to a lack of fit between programs and their supposed beneficiaries (Korten 1980). In effect, there is a concern that such an application of the principles may violate principle $2 \mathrm{~A}$, i.e., congruency between rules and local conditions.

Young (2002) contrasts the design principles approach with what he calls a diagnostic approach to analysis. He states, "Because design principles are framed as universal propositions, they should hold across all members of the relevant universe of cases" (Young 2002:170). Agrawal (2002:49) makes a similar argument that the principles "are expressed as general features of long-lived, successful commons management rather than as relationships between characteristics of the constituent analytical units or as factors that depend for their efficacy on the presence (or absence) of other variables." 
In lieu of the design principles approach, Young (2002) favors a diagnostic process of subdividing environmental problems into subsets to tease out the institutional implications of different types of environmental problems. Indeed, Ostrom (2007, 2009) is moving in a diagnostic direction as well. She states, "We need to recognize and understand the complexity to develop diagnostic methods to identify combinations of variables that affect the incentives and actions of actors under diverse governance systems" (Ostrom 2007:15181).

Although we think that there are likely limitations in generalizing the design principles to larger-scale cases, we argue that the dichotomy between diagnostic and design principle approaches is false, at least in this context. A diagnostic approach most fundamentally involves two tasks: identifying an environmental problem, and identifying the governance arrangements that are most likely to be effective in resolving that problem. To do this most effectively, one needs to construct nested typologies of environmental problems and governance arrangements. If this can be done, it may be possible, with accumulated empirical evidence, to match types of governance arrangements to types of problems that they have proven to be effective in resolving. A nested typology contains types that are arranged hierarchically, with each level being a subdivision of types from the previous level into further subtypes. The instances belonging to types at each successive level are more similar than are those at previous levels.

One very basic example of a subdivision that could form a basis for this process is the distinction between two types of collective-action problems: CPR problems and public goods problems. In addition, a division is often made between environmental (pollution) problems and natural resource (consumption) problems. The implications for which governance arrangements are most effective will likely differ between these types of problems. Furthermore, there are many different subtypes of environmental and natural resource problems. Sulfur dioxide $\left(\mathrm{SO}_{2}\right)$ emissions and carbon dioxide $\left(\mathrm{CO}_{2}\right)$ emissions are both environmental pollution problems, but various lower-level properties of these problems favor different types of governance arrangements (Stavins 1998). As such, a tradable emissions permit system may not be as effective in limiting $\mathrm{CO}_{2}$ emissions as it has been in limiting $\mathrm{SO}_{2}$ emissions under Title 4 of the United States' 1990 Clean Air Act amendments.
Likewise, one needs to consider multiple, nested types of governance arrangements. Beyond the basic trichotomy of markets, states, and communities, one needs to consider multiple forms of each of these ideal types. We think that the design principles can be placed effectively within such a nested typology of governance arrangements. For example, we could specify multiple types of monitoring (principle 4), conflict resolution mechanisms (principle 6), and institutional nesting (principle 8). Indeed, two basic distinctions we have already made contrast environmental and social monitoring and distinguish between horizontal and vertical linkages. Different subtypes of these arrangements will likely be more effective in resolving different types of problems.

As such, we see the diagnostic and design principles approaches to be potentially complementary, instead of mutually exclusive. Although we do not agree with the critique of the design principles as being tied to a simplistic blueprint approach, we think that a significant amount of work is needed to combine them with a well-developed diagnostic approach.

\section{Reformulation of design principles}

The principles we reformulate are 1,2 , and 4 . We propose that principles $3,5,6,7$, and 8 remain as they are. We divided each of the first two principles into two components for our analysis. We found that these individual components often made important contributions to the outcomes of cases and conclusions of studies. Thus, we recommend dividing principles 1 and 2 into their component parts. One addition could be made to principle 1: congruence between user and resource boundaries. We also divide principle 4 (monitoring) into two components, but not along the lines used in conducting the analysis. Rather, we divide it into a principle regarding users monitoring one another's behavior (social monitoring) and users monitoring the condition of the resource (environmental monitoring). Each of these was often found to be important in determining the success of communitybased natural resource management. Thus, we propose a modified set of design principles (Table 4). 
Table 4. List of proposed, modified design principles.

\begin{tabular}{ll}
\hline Principle & Description \\
\hline 1A & User boundaries: Clear boundaries between legitimate users and nonusers must be clearly defined. \\
1B & $\begin{array}{l}\text { Resource boundaries: Clear boundaries are present that define a resource system and separate it from the larger } \\
\text { biophysical environment. }\end{array}$
\end{tabular}

2A Congruence with local conditions: Appropriation and provision rules are congruent with local social and environmental conditions.

2B Appropriation and provision: The benefits obtained by users from a common-pool resource (CPR), as determined by appropriation rules, are proportional to the amount of inputs required in the form of labor, material, or money, as determined by provision rules.

3 Collective-choice arrangements: Most individuals affected by the operational rules can participate in modifying the operational rules.

4A Monitoring users: Monitors who are accountable to the users monitor the appropriation and provision levels of the users.

4B Monitoring the resource: Monitors who are accountable to the users monitor the condition of the resource.

5 Graduated sanctions: Appropriators who violate operational rules are likely to be assessed graduated sanctions (depending on the seriousness and the context of the offense) by other appropriators, by officials accountable to the appropriators, or by both.

6 Conflict-resolution mechanisms: Appropriators and their officials have rapid access to low-cost local arenas to resolve conflicts among appropriators or between appropriators and officials.

7 Minimal recognition of rights to organize: The rights of appropriators to devise their own institutions are not challenged by external governmental authorities.

8 Nested enterprises: Appropriation, provision, monitoring, enforcement, conflict resolution, and governance activities are organized in multiple layers of nested enterprises.

\section{CONCLUSION}

We attempted to synthesize a large number of studies that examined Ostrom's (1990) design principles. Empirically, we think that the principles are well supported. The most trenchant critiques were abstract, rather than empirical. This does not mean that the principles are complete; their incompleteness is the most important empirical critique we found in the literature. Other factors such as the size of user groups, differing types of heterogeneity within or between user groups, and the type of government regime within which users operate are clearly important in many cases (see Agrawal 2002).
Analyses similar to ours, with a focus on these other relevant factors from several disciplinary perspectives, could be a fruitful source of progress in this field. Much work remains to be done to augment the biophysical sophistication of CPR case studies to understand how institutional variables interact with biophysical variables to produce outcomes. Finally, work from cultural and political ecology could serve as a useful complement to the primarily political science orientation embodied in the principles.

As such, a probabilistic, rather than deterministic, interpretation of the design principles is warranted. Likewise, we remain uncertain as to whether the principles may apply to systems at a variety of 
scales. Ultimately, however, the design principles are robust to empirical testing in our analysis of 91 studies. Thus, we conclude that they are a sound basis for future research conducted to further disentangle the interactive effects of relevant variables, both within and across multiple environmental and social scales.

Aside from our empirical analysis, we dealt with an important theoretical debate regarding the principles: Are they inherently part of a blueprint approach to CPR management or can they be combined with a more diagnostic approach? We think the latter is the case, and this points us in a specific direction for future research. Each of the aforementioned empirical complications could likely be addressed by approaching CPR management from a diagnostic perspective. This is a process that helps to sort out what is important in a CPR setting, when, and why. We hope to see and plan to participate in future work to develop this approach further.

Responses to this article can be read online at: http://www.ecologyandsociety.org/voll5/iss4/art38/ responses/

\section{Acknowledgments:}

This paper is a revision of an earlier report to the Lincoln Institute of Land Policy, Cambridge, Massachusetts, USA, entitled Design Principles Are not Blue Prints, but Are They Robust?: a Metaanalysis of 112 Studies. Financial support from the Lincoln Institute of Land Policy, the National Science Foundation (grant no. BCS-0527744), and La Fundación Caja Madrid: Departamento de Becas, Investigación y Universidades is deeply appreciated. We thank Xavier Basurto, Bryan Bruns, and Elinor Ostrom for their feedback on the manuscript, and Patty Lezotte for editing the final draft.

\section{LITERATURE CITED}

Agrawal, A. 2002. Common resources and institutional sustainability. Pages 41-86 in E. Ostrom, T. Dietz, N. Dolšak, P. C. Stern, S. Stovich, and E. U. Weber, editors. The drama of the commons. National Academy Press, Washington, D.C., USA.

Agrawal, A., and A. Chhatre. 2006. Explaining success in the commons: community forest governance in the Indian Himalaya. World Development 34(1):149-166.

Agrawal, A., and G. Yadama. 1997. How do local institutions mediate market and population pressures on resources? Forest panchayats in Kumaon, India. Development and Change $\mathbf{2 8}$ (3):435-465.

Bardhan, P. 2000. Irrigation and cooperation: an empirical analysis of 48 irrigation communities in south India. Economic Development and Cultural Change 48(4):847-865.

Berkes, F. 2002. Cross-scale institutional linkages: perspectives from the bottom up. Pages 293-321 in E. Ostrom, T. Dietz, N. Dolšak, P. C. Stern, S. Stovich, and E. U. Weber, editors. The drama of the commons. National Academy Press, Washington, D.C., USA.

Berkes, F. 2005. Commons theory for marine resource management in a complex world. Senri Ethnological Studies 67:13-31.

Berkes, F. 2006. From community-based resource management to complex systems: the scale issue and marine commons. Ecology and Society 11(1): 45. [online] URL: http://www.ecologyandsociety.org/ vol11/iss 1/art45/.

Berkes, F., J. Colding, and C. Folke. 2000. Rediscovery of traditional ecological knowledge as adaptive management. Ecological Applications 10 (5):1251-1262.

Berkes, F., and C. Folke, editors. 1998. Linking social and ecological systems: management practices and social mechanisms for building resilience. Cambridge University Press, Cambridge, UK.

Blaikie, P. 2006. Is small really beautiful? Community-based natural resource management in Malawi and Botswana. World Development 34 (11):1942-1957.

Bruns, B. 2007. Community priorities for water rights: some conjectures on assumptions, principles 
and programmes. Pages 28-45 in B. van Koppen, M. Giordano, and J. Butterworth, editors. Community-based water law and water resource management reform in developing countries. CABI, Wallingford, UK.

Cinner, J. E., and T. R. McClanahan. 2006. Socioeconomic factors that lead to overfishing in small-scale coral reef fisheries of Papua New Guinea. Environmental Conservation 33(1):73-80.

Cinner, J. E., A. Wamukota, H. Randriamahazo, and A. Rabearisoa. 2009. Toward institutions for community-based management of inshore marine resources in the Western Indian Ocean. Marine Policy 33(3):489-496.

Cleaver, F. 1999. Paradoxes of participation: questioning participatory approaches to development. Journal of International Development 11 (4):597-612.

Cleaver, F. 2000. Moral ecological rationality, institutions and the management of common property resources. Development and Change $\mathbf{3 1}$ (2):361-383.

Coward, W. E., Jr. 1977. Irrigation management alternatives: themes from indigenous irrigation systems. AgriculturalAdministration 4(3):223-237.

Cox, M. 2008. Balancing accuracy and meaning in common-pool resource theory. Ecology and Society 13(2): 44. [online] URL: http://www.ecologyandso ciety.org/vol13/iss2/art44/.

Cox, M. 2010. Exploring the dynamics of socialecological systems: the case of the Taos Valley acequias. Dissertation. Indiana University, Bloomington, Indiana, USA.

Demsetz, H. 1967. Toward a theory of property rights. American Economic Review 57(2):347-359.

Feeny, D., F. Berkes, B. J. McCay, and J. M. Acheson. 1990. The tragedy of the commons: twenty-two years later. Human Ecology 18(1):1-19.

Field, A. 2009. Discovering statistics using SPSS. Third edition. Sage Publications, London, UK.

Gautam, A. P., and G. P. Shivakoti. 2005. Conditions for successful local collective action in forestry: some evidence from the hills of Nepal. Society and Natural Resources 18(2):153-171.
Ghate, R., and H. Nagendra. 2005. Role of monitoring in institutional performance: forest management in Maharashtra, India. Conservation and Society 3(2):509-532.

Gibson, C. C. 2001. Forest resources: institutions for local governance in Guatemala. Pages 71-89 in J. Burger, E. Ostrom, R. B. Norgaard, D. Policansky, and B. D. Goldstein, editors. Protecting the commons: a framework for resource management in the Americas. Island Press, Washington, D.C., USA.

Gordon, H. S. 1954. The economic theory of a common-property resource: the fishery. Journal of Political Economy 62(2):124-142.

Guillet, D. W. 1992. Covering ground: communal water management and the state in the Peruvian highlands. University of Michigan Press, Ann Arbor, Michigan, USA.

Hanna, S., C. Folke, and K.-G. Mäler. 1995. Property rights and environmental resources. Pages 15-29 in S. Hanna and M. Munasinghe, editors. Property rights and the environment: social and ecological issues. The World Bank, Washington, D. C., USA.

Hardin, G. 1968. The tragedy of the commons. Science 162(3859):1243-1248.

Harkes, I. H. T. 2006. Fisheries co-management, the role of local institutions and decentralisation in Southeast Asia: with specific reference to marine sasi in Central Maluku, Indonesia. Dissertation. Leiden University, Leiden, The Netherlands.

Hayek, F.A. 1945. The use of knowledge in society. American Economic Review 35(4):519-530.

Johnson, C. A. 1997. Rules, norms and the pursuit of sustainable livelihoods. Working Paper 52. Institute of Development Studies, University of Sussex, Brighton, UK. [online] URL: http://www.e ldis.org/assets/Docs/40332.html.

Johnson, K. A., and K. C. Nelson. 2004. Common property and conservation: the potential for effective communal forest management within a national park in Mexico. Human Ecology 32 (6):703-733.

Klooster, D. 2000. Institutional choice, community, and struggle: a case study of forest co-management in Mexico. World Development 28(1):1-20. 
Korten, D. C. 1980. Community organization and rural development: a learning process approach. Public Administration Review 40(5):480-511.

Lane, C., and I. Scoones. 1993. Barabaig natural resource management. Pages 93-119 in M. D. Young and O. T. Solbirg, editors. The world's savannas: economic driving forces, ecological constraints, and policy options for sustainable land use. UNESCO, Paris, France.

Leach, M., R. Mearns, and I. Scoones. 1999. Environmental entitlements: dynamics and institutions in community-based natural resource management. World Development 27(2):225-247.

López Gunn, E., and N. Hernandez Mora. 2001. La gestión colectiva de las aguas subterráneas en La Mancha: análisis comparativo. Pages 405-474 in N. Hernandez Mora and M. R. Llamas, editors. La economía del agua subterránea y su gestión collectiva. Fundación Marcelino Botín and MundiPrensa, Madrid, Spain.

Mandondo, A. 2001. Use of woodland resources within and across villages in a Zimbabwean communal area. Agriculture and Human Values 18 (2):177-194.

Morrow, C. E., and R. W. Hull. 1996. Donorinitiated common pool resource institutions: the case of the Yanesha Forestry Cooperative. World Development 24(10):1641-1657.

Mosse, D. 1997. The symbolic making of a common property resource: history, ecology and locality in a tank-irrigated landscape in South India. Development and Change 28(3):467-504.

National Research Council, editor. 1986. Proceedings of the conference on common property resource management. National Academy Press, Washington, D.C., USA.

Niamir-Fuller, M. 1998. The resilience of pastoral herding in Sahelian Africa. Pages 250-284 in F. Berkes and C. Folke, editors. Linking social and ecological systems: management practices and social mechanisms for building resilience. Cambridge University Press, Cambridge, UK.

Nilsson, T. 2001. Management of communal grazing land: a case study on institutions for collective action in Endabeg Village, Tanzania.
Thesis. Royal Institute of Technology, Stockholm, Sweden.

North, D. C. 1990. Institutions, institutional change, and economic performance. Cambridge University Press, Cambridge, UK.

Ostrom, E. 1990. Governing the commons: the evolution of institutions for collective action. Cambridge University Press, Cambridge, UK.

Ostrom, E. 2007. A diagnostic approach for going beyond panaceas. Proceedings of the National Academy of Sciences 104(39):15181-15187.

Ostrom, E. 2009. A general framework for analyzing sustainability of social-ecological systems. Science 325(5939):419-422.

Pagdee, A., Y. Kim, and P. J. Daugherty. 2006. What makes community forest management successful: a meta-study from community forests throughout the world. Society and Natural Resources 19(1):33-52.

Pinkerton, E., and M. Weinstein. 1995. Fisheries that work: sustainability through community-based management. David Suzuki Foundation, Vancouver, Canada.

Pomeroy, R. S., B. M. Katon, and I. Harkes. 2001. Conditions affecting the success of fisheries comanagement: lessons from Asia. Marine Policy 25 (3):197-208.

Rowland, M. 2005. A framework for resolving the transboundary water allocation conflict conundrum. Ground Water 43(5):700-705.

Ruddle, K. 1996. Boundary definition as a basic design principle of traditional fishery management systems in the Pacific Islands. Geographische Zeitschrift 84(2):94-102.

Sandström, C., and C. Widmark. 2007. Stakeholders' perceptions of consultations as tools for co-management - a case study of the forestry and reindeer herding sectors in northern Sweden. Forest Policy and Economics 10(1-2):25-35.

Sarker, A., and T. Itoh. 2001. Design principles in long-enduring institutions of Japanese irrigation common-pool resources. Agricultural Water Management 48(2):89-102. 
Schlager, E., W. Blomquist, and S. Y. Tang. 1994. Mobile flows, storage, and self-organized institutions for governing common-pool resources. Land Economics 70(3):294-317.

Schmidtz, D., and E. Willott. 2003. Reinventing the commons: an African case study. U.C. Davis Law Review 37(1):203-232.

Scott, J. C. 1998. Seeing like a state: how certain schemes to improve the human condition have failed. Yale University Press, New Haven, Connecticut, USA.

Singleton, S., and M. Taylor. 1992. Common property, collective action and community. Journal of Theoretical Politics 4(3):309-324.

Skjølsvold, T. M. 2008. The institutional reality of common pool resources. Thesis. Norwegian University of Science and Technology, Trondheim, Norway.

Stavins, R. N. 1998. What can we learn from the grand policy experiment? Lessons from $\mathrm{SO}_{2}$ allowance trading. Journal of Economic Perspectives 12(3):69-88.

Steins, N.A. 1999. All hands on deck: an interactive perspective on complex common-pool resource management based on case studies in the coastal waters of the Isle of Wight (UK), Connemara (Ireland), and the Dutch Wadden Sea. Dissertation. University of Wageningen, Wageningen, The Netherlands.

Steins, N.A., and V. M. Edwards. 1999. Collective action in common-pool resource management: the contribution of a social constructivist perspective to existing theory. Society and Natural Resources 12 (6):539-557.

Trawick, P. B. 2001. Successfully governing the commons: principles of social organization in an Andean irrigation system. Human Ecology 29 (1):1-25.

Tucker, C. M. 1999. Common property design principles and development in a Honduran community. Fletcher Journal of Development Studies XV. [online] URL: http://fletcher.tufts.edu/ praxis/archives/xv/Tucker.pdf.
Tucker, C. M., J. C. Randolph, and E. J. Castellanos. 2007. Institutions, biophysical factors and history: an integrative analysis of private and common property forests in Guatemala and Honduras. Human Ecology 35(3):259-274.

Turner, M. D. 1999. Conflict, environmental change, and social institutions in dryland Africa: limitations of the community resource management approach. Society and Natural Resources 12 (7):643-657.

Yandle, T. 2006. Sharing natural resource management responsibility: examining the New Zealand rock lobster co-management experience. Policy Sciences 39(3):249-278.

Young, O. R. 2002. The institutional dimensions of environmental change: fit, interplay, and scale. MIT Press, Cambridge, Massachusetts, USA. 